\title{
AVALIAÇÃO DO CRESCIMENTO INICIAL E DA ALOCAÇÃO DE BIOMASSA SECA EM GUANXUMA
}

Victor Mouzinho Spinelli', Marcio Gonçalves da Silva ${ }^{2}$, Raimunda Nonata Oliveira da Silva ${ }^{2}$, Tainan Lopes de Almeida ${ }^{2}$, Luis Eduardo Panozzo ${ }^{3}$

${ }^{1}$ Doutorando em Fisiologia Vegetal do Departamento de Botânica do Instituto de Biologia da Universidade Federal de Pelotas (mouzinhovs@yahoo.com.br) Pelotas Brasil

${ }^{2}$ Pós-graduandos em Ciência e Tecnologia de Sementes da Universidade Federal de Pelotas, Pelotas - RS, Brasil;

${ }^{3}$ Professor doutor da Faculdade de Agronomia Eliseu Maciel do Departamento de Fitotecnia da Universidade Federal de Pelotas - RS, Brasil.

Recebido em: 08/04/2016 - Aprovado em: 30/05/2016 - Publicado em: 20/06/2016 DOI: 10.18677/Enciclopedia_Biosfera_2016_016

\begin{abstract}
RESUMO
A presença do guanxuma (Sida rhombifolia L.) em lavouras de diferentes culturas interferem negativamente no desenvolvimento e na produtividade diferentes cultivares promovendo competição por recursos do meio ambiente. Para avaliar o desenvolvimento vegetal e inferir sobre a contribuição de diferentes processos fisiológicos no desenvolvimento vegetal, a análise de crescimento é levada em consideração. O experimento foi conduzido em casa-de-vegetação, na Universidade Federal de Pelotas (UFPEL), durante a estação de crescimento 2006/07. O delineamento experimental adotado foi do tipo inteiramente casualizado, com cinco tratamentos e quatro repetições. Os tratamentos foram cinco épocas de avaliação: 11, 22, 33, 44 e aos 55 dias após emergência (DAE), com intervalos de 11 dias entre cada coleta considerando-se como o dia zero a data de germinação das sementes. Foi possível observar que ao longo do experimento as plantas de guaxuma $(S$. rhombifolia) investem mais biomassa fresca e seca no desenvolvimento do sistema radicular.
\end{abstract}

PALAVRAS- CHAVE: Sida rhombifolia L., crescimento inicial, medidas lineares fitotecnias.

\section{EVALUATION OF GROWTH ALLOCATION IN THE AREA PART AND ROOT SIDA}

\section{ABSTRACT}

The presence of prickly sida (Sida rhombifolia L.) crops in different cultures interfere negatively in developing and promoting different cultivars productivity competition for environmental resources. To evaluate plant development and to infer the contribution of different physiological processes in plant development, growth analysis is taken into account. The experiment was conducted in a greenhouse at the Federal University of Pelotas (UFPEL) during the growing season 2006/07. The experimental design was fully randomized design with five treatments and four replications. The ENCICLOPÉDIA BIOSFERA, Centro Científico Conhecer - Goiânia, v.13 n.23; p. 1742016 
treatments were five evaluation periods: 11, 22, 33, 44 and 55 days after emergence (DAE), at intervals of 11 days between each collection considering as day zero date of seed germination.As conclusion of the experiment, it is emphasized that plants prickly guaxuma $(S$. rhombifolia) biomass invest biomass more significantly during growth at root.

KEYWORDS: Sida rhombifolia L., initial growth, measures linear fitotecnias

\section{INTRODUÇÃO}

Estudos do crescimento e desenvolvimento vegetal em plantas daninhas é de fundamental importância para o entendimento da interferência competitiva por recursos nutricionais e fatores ecológicos do meio (água, luz e $\mathrm{CO}_{2}$ ), uma vez que contribui para a redução sobre os componentes de rendimento de cultivos agrícolas de interesse econômico (GALON et al., 2015).

A guanxuma (Sida rhombifolia L.) é uma planta perene e subarbustiva da família Malvaceae, particularmente resistente às condições adversas de clima e solo (BIANCO et al., 2014). Nativa da América, esta espécie de planta daninha apresenta ampla variabilidade genética devido a sua capacidade de disseminação por via seminífera, sendo este um mecanismo de sobrevivência importante desta espécie (FLECK et al., 2003). De acordo com BRAGA et al. (2012), vários fatores influenciam a disseminação desta espécie, como a adaptabilidade ecológica, prolificidade de indivíduos, longevidade, alta capacidade de florescimento e a capacidade de emergir a partir de grandes profundidades no perfil do solo.

Além da competição por recursos do ambiente, a guanxuma pode atuar como hospedeira de microplasmas que causam a doença conhecida como virose das malváceas (SOUZA et al., 2012). No Brasil, vários são os trabalhos que relatam a interferência causada pelas espécies de Sida sp. nos diferentes sistemas produtivos como, por exemplo, em pastagens de várzea (FERREIRA et al., 2014), pinhãomanso (FEY et al., 2013), feijão (VOGT et al., 2014), sorgo (SILVA et al., 2014), cana-de-açúcar (OLIVEIRA \& SIMÔES, 2014) e café (SIQUEIRA et al., 2014).

Para avaliar o acúmulo de fitomassa durante um intervalo de tempo que descreva as condições morfofisiológicas das plantas, a análise de crescimento é levada em consideração, uma vez que permite ampliar as causas da variação de crescimento entre plantas geneticamente diversas ou dentro de plantas da mesma espécie podendo ser realizada através de medições de medidas lineares: altura de planta, comprimento e diâmetro do caule, comprimento e largura de folha, comprimento de raiz e medidas de superfície (principalmente pela medição da superfície da lâmina foliar) (BENINCASA, 2003; TAIZ \& ZAIGER, 2013).

O estudo dessas características é uma ferramenta importante para se estabelecer o manejo de plantas daninhas em diferentes sistemas produtivos e fornece subsídios para o entendimento das respostas morfológicas e fisiológicas das espécies em diversas situações de cultivo, possibilitando planejar manejos adequados que justifiquem a utilização do controle químico antes de iniciar a interferência sobre a cultura ( FLECK et al., 2004 ; LAMEGO et al., 2013; AGOSTINETTO et al., 2013; IKEDA \& INOUE, 2015). O objetivo da pesquisa foi caracterizar padrões morfológicos de alocação da parte aérea e raiz de Sida rhombifolia em condições de casa-de-vegetação. 


\section{MATERIAL E MÉTODOS}

O experimento foi conduzido em casa-de-vegetação, na Faculdade de Agronomia Eliseu Maciel, pertencente à Universidade Federal de Pelotas (UFPel), localizada no Município de Capão do Leão-RS, durante a estação de crescimento 2006/07.

O solo utilizado no experimento é classificado como Planossolo Hidromórfico Eutrófico Solódico, pertencente à Unidade de Mapeamento Pelotas (EMBRAPA, 2009). Sendo esterilizado por três vezes em autoclave a $120{ }^{\circ} \mathrm{C}$ por duas horas ; para evitar a germinação e emergência de plantas a partir do banco de sementes. Não foi realizada adubação de base, pois o solo foi coletado na área experimental, cuja fertilidade é corrigida anualmente.

Cada unidade experimental foi composta por vaso com capacidade de 550 gramas de solo. Foram utilizadas sementes oriundas de plantas de Sida rhombifolia L., provenientes de lavoura, as quais foram devidamente identificadas com auxílio de bibliografia. Após semeadura e emergência das plântulas, foram realizados desbastes até estabelecer duas plantas por vaso. Os vasos foram perfurados na sua base, colocados em bandejas com água para que a irrigação ocorresse por capilaridade. A disponibilidade hídrica foi monitorada diariamente através da capacidade de campo com uma umidade equivalente a $80 \%$, monitorado pelo conteúdo volumétrico de água e um sensor de temperatura (Decagon's 5TM, Decagon Devices Inc., Pullman, WA, EUA), acoplada a um dispositivo ProCheck (Decagon Devices Inc., Pullman, WA, EUA) e quando necessário foi realizada a irrigação manual.

O delineamento experimental adotado foi do tipo inteiramente casualizado, com cinco tratamentos e quatro repetições. Os tratamentos foram cinco épocas de avaliação: 11, 22, 33, 44 e aos 55 dias após emergência (DAE), com intervalos de 11 dias entre cada coleta considerando-se como o dia zero a data de germinação das sementes. Em cada avaliação, oito plantas sendo duas por repetição foram aleatoriamente amostradas pelo método destrutivo, onde passaram por lavagem em água corrente, sobretudo para retirada do solo remanescente nas raízes, e, em seguida, tiveram suas variáveis analisadas.

Para todas as épocas de avaliação, as variáveis foram obtidas a partir de amostras de oito plantas (duas/repetições), onde avaliou-se a altura da parte aérea, comprimento de raiz, área foliar e percentual de massa seca da parte aérea (MSPA), subdivididos em folha (MSF) e massa seca do caule (MSC), e massa seca de raízes (MSR)

A estatura e o comprimento de raízes das plantas foram obtidos com a utilização de régua graduada, sendo expressos em centímetros. A AF foi obtida com auxílio do medidor de área foliar modelo LICOR LI-3100. Logo após, foi realizada a pesagem de massa fresca da parte aérea (MFPA) e massa fresca de raiz (MFR), utilizando balança centesimal e os resultados expressos em gramas. $O$ material amostrado para obtenção da MSPA e MSR foi colocado em sacos de papel e estes em estufa a temperatura de $60{ }^{\circ} \mathrm{C}$ até atingirem mass a constante. Após secagem, foi realizada pesagem, utilizando balança centesimal para obtenção da MSPA e MSR.

Os dados obtidos foram submetidos à análise de regressão e o modelo foi escolhido levando-se em consideração a lógica do fenômeno biológico e o valor do coeficiente de determinação. 


\section{RESULTADOS E DISCUSSÃO}

Comparando as duas variáveis, observa-se a partir do coeficiente angular da regressão linear $(0,20)$ para altura de planta e $(0,31)$ para comprimento de raiz que a segunda variável evidenciou uma diferença de $55 \%$ maior que a variável altura, com expressivo crescimento radicular, detectado aos 11 DAE e pleno desenvolvimento vegetativo até o fim da avaliação do experimento (Figura 1).

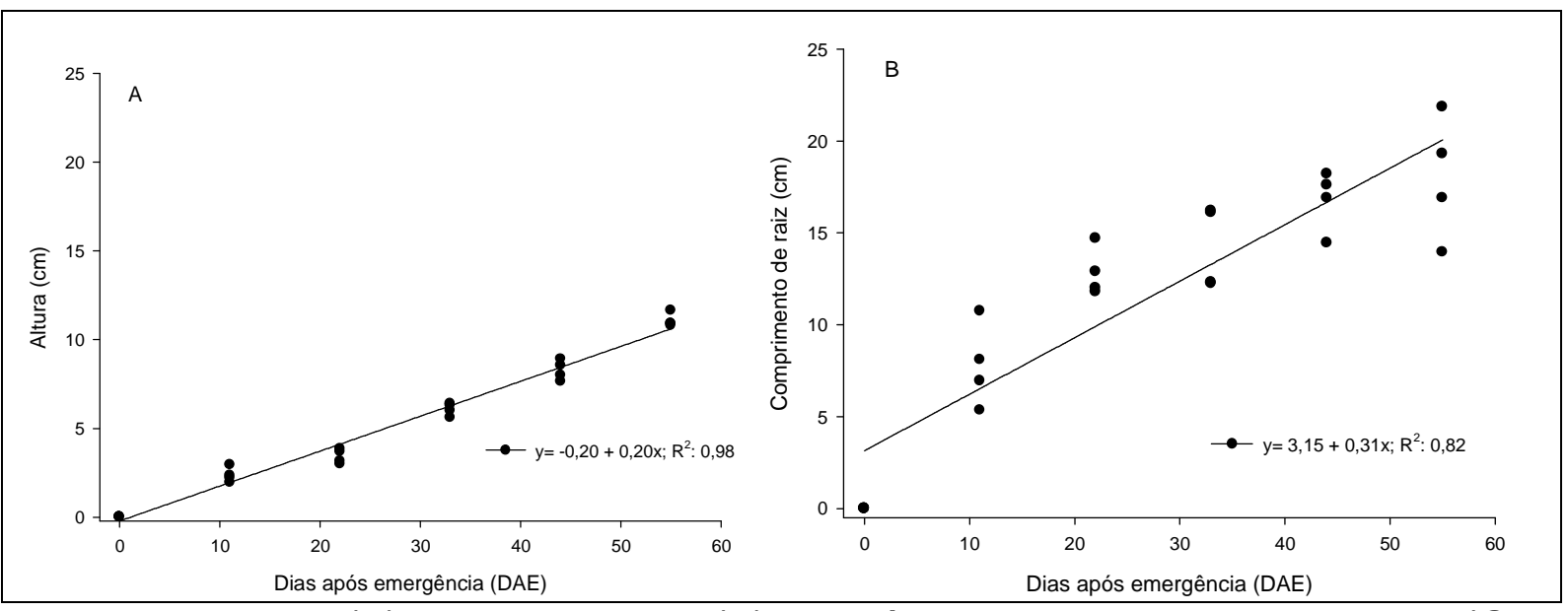

FIGURA 1 Altura (A) e comprimento (B) de raízes de plantas de guanxuma (Sida rhombifolia L.), avaliadas aos $11,22,33,44$ e aos 55 dias após a emergência (DAE). UFPEL/FAEM, Pelotas-RS, 2006/07. ( $R^{2}$ : Coeficiente de determinação; * Significativo a $1 \%$ de probabilidade).

Aos 22 DAE verifica-se que o acréscimo ocorreu de forma mais acentuada para o comprimento de raiz, tendo apresentado uma diferença de aproximadamente $10 \mathrm{~cm}$ em relação à altura, demonstrando a elevada capacidade dessa espécie em crescimento radicular principalmente próximo do final do período de avaliação, alcançando valores médios de $22 \mathrm{~cm}$ (Figura 1). Esse comportamento tem sido observado em todas as plantas daninhas estudadas e é atribuído à melhor fixação inicial da planta no substrato, aumentando assim o contato dos nutrientes por interceptação radicular e levando ao rápido acúmulo pelas raízes (COELHO et al., 2013).

Observou-se que para a variável área foliar o ganho de biomassa seguiu o comportamento inicial da parte aérea como consequência da maior tendência á produção de estruturas reprodutivas, contudo aos 33 DAE verifica-se um rápido crescimento, tendo atingido o ponto máximo de aproximadamente $42 \mathrm{~cm}^{2}$ aos 55 DAE (Figura 2). A análise de medição da área foliar, dentro da experimentação em fitotecnia, permite ao pesquisador obter indicativo de resposta de tratamentos aplicados e lidar com uma variável que se relaciona diretamente com a capacidade fotossintética, interceptação da luze a absorção de herbicida (SEVERINO et al. 2004). 


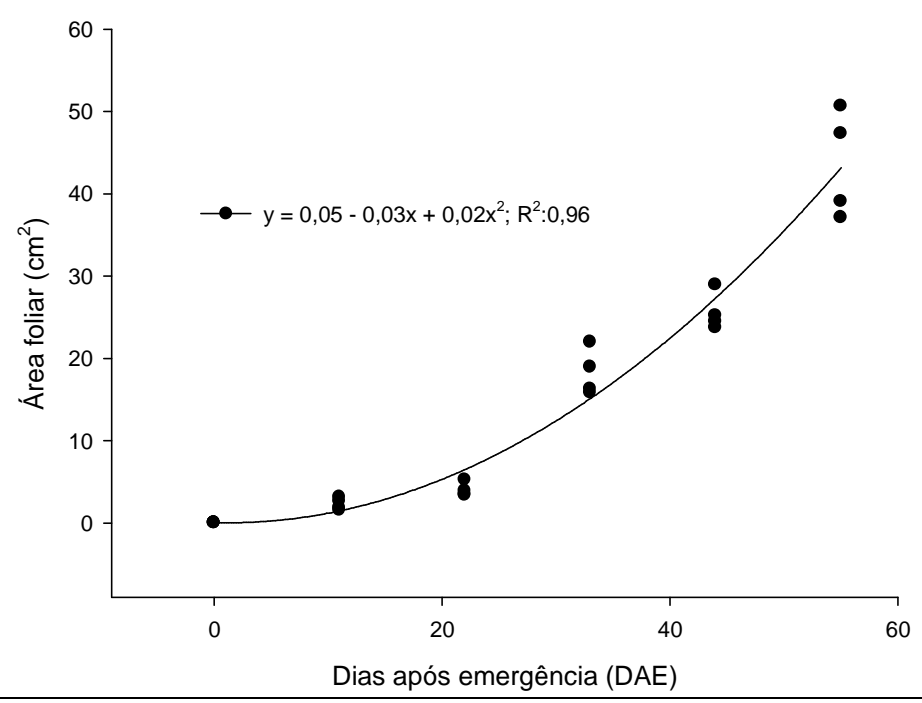

FIGURA 2 Área foliar de plantas de guanxuma (Sida rhombifolia L.), avaliadas aos 11, 22, 33, 44 e aos 55 dias após a emergência (DAE). UFPEL/FAEM, Pelotas-RS, 2006/07. ( $R^{2}$ : Coeficiente de determinação; * Significativo a $1 \%$ de probabilidade).

Por sua vez, os resultados da distribuição percentual de massa seca permitem verificar que no início do experimento (11 DAE) as folhas foram o principal órgão acumulador, tendo apresentado aproximadamente $64 \%$ do total da massa seca acumulada, enquanto que para a raiz foi de $22 \%$ e caule $16 \%$ da biomassa seca total na primeira avaliação (Figura 3).

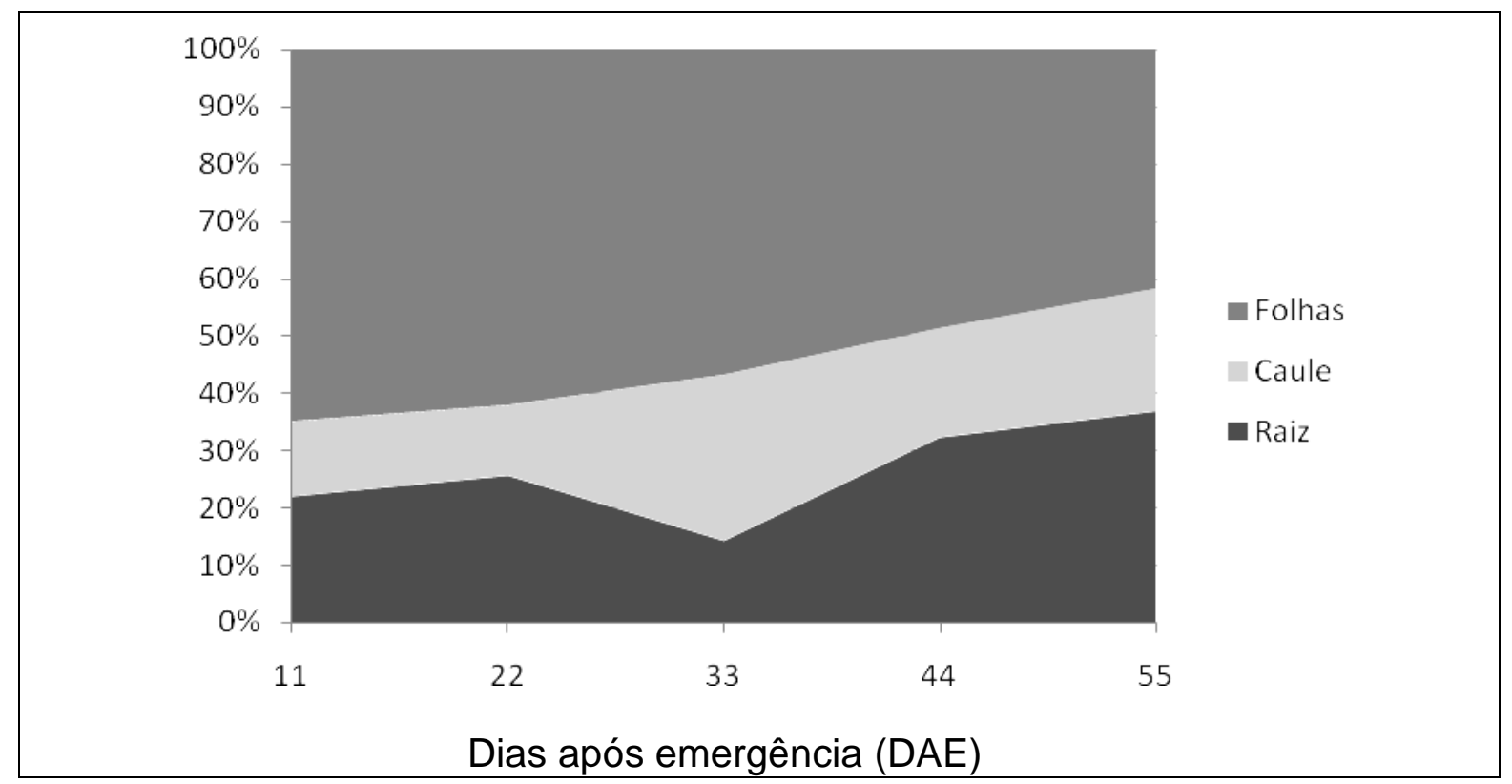

FIGURA 3. Distribuição percentual de massa seca nas das diferentes partes das plantas de guanxuma (Sida rhombifolia L.), avaliadas aos 11, 22, 33, 44 e aos 55 dias após a emergência (DAE). UFPEL/FAEM, Pelotas-RS, 2006/07. 
Em relação à biomassa seca total de planta, verifica-se que aos 11 DAE a distribuição da massa concentrou-se principalmente na folha com $64 \%$, seguido da raiz com $22 \%$ e do caule com $14 \%$. Tal distribuição é influenciada pela necessidade do guanxuma em investir no aparato fotossintético e converter substâncias inorgânicas em esqueletos de carbono, propiciando ao principal órgão de absorção de água e sais minerais nesta fase inicial de crescimento o desenvolvimento natural da espécie. No entanto, aos 33 DAE, o guanxuma decresceu para $12 \% 0$ investimento em MSR. Contudo, aos 44 DAE, verifica-se um aumento gradual da MSR em detrimento da partição no caule e na folha perdurando até os 55 DAE com uma alocação de biomassa de $33 \%$, seguido das diminuições da MSF e MSC (Figura 3).

\section{CONCLUSÃO}

As plantas de guaxuma ( $S$. rhombifolia) investem mais biomassa fresca e seca no desenvolvimento do sistema radicular.

\section{REFERÊNCIAS}

AGOSTINETTO, D. FONTANA, L. C.; VARGAS, L.; MARKUS, C.; OLIVEIRA, E. Habilidade competitiva relativa de milhã em convivência com arroz irrigado e soja. Pesquisa Agropecuária Brasileira, v. 48, n. 10, p. 1315-1322, 2013. Disponível em: <http://dx 10.1590/S0100-204X2013001000002> doi: org/0.1590/S0100204X2013001000002

BENINCASA, M. M. P. Análise de crescimento de plantas, noções básicas. 2 ed. Jaboticabal: FUNEP, 2003. 41 p.

BIANCO, S.; CARVALHO, L.B.; BIANCO, M.S. Crescimento e nutrição mineral de Sida rhombifolia. Planta Daninha, Viçosa-MG, v. 32, n. 2, p. 311-317, 2014. Disponível em: Disponível em: <http://dx.doi.org/10.1590/S010083582014000200008> doi: org/10.1590/S0100-83582014000200008

BRAGA, R. R.; CURY, J. P.; SANTOS, J. B dos.; BYRRO, E. C. M.; SILVA, D. V.; CARVALHO, F. P.; RIBEIRO, K. G. Ocorrência de plantas daninhas no sistema lavoura-pecuária em função de sistemas de cultivo e corretivo de acidez. Revista Ceres, v. 59, n. 5, p. 646-653, 2012. Disponível em: http://dx.doi.org/10.1590/S0034737X2012000500010 > doi: org/10.1590/S0034-737X2012000500010

COELHO, M. E. H.; FREITAS, F. C. L.; XAVIER, J. L.; CUNHA, L.; DOMBROSKI, J. L. D.; SANTANA, F. A. O. Interferência de plantas daninhas no crescimento do pimentão nos sistemas de plantio direto e convencional. Revista Caatinga , v. 26, n. 4, $\quad$ p. $19 \quad-\quad 30, \quad 2013.2$ Disponível em: <http://www.redalyc.org/articulo.oa?id=237129900003> doi:org/237129900003.

IKEDA, F. S.; INOUE, M. H. Manejo Sustentável de Plantas Daninhas em Sistemas de Produção Tropical, Embrapa, p. 117, 2015.

LAMEGO, F. P.; RUCHEL, Q.; KASPARY, T. E.; GALLON, M.; BASSO, C. J.; SANTI, A. L. Habilidade competitiva de cultivares de trigo com plantas daninhas. Planta 
daninha, v.31 n.3, 2013. Disponível em: < http://dx.doi.org/10.1590/S010083582013000300004> doi:org/10.1590/S0100-83582013000300004

FERREIRA, E. A.; FERNANDEZ, A. G.; SOUZA, C. P.; FELIPE, M. A; SANTOS, J. B.; SILVA, D. V.; GUIMARÃES, F. A. R. Levantamento fitossociológico de plantas daninhas em pastagens degradadas do Médio Vale do Rio Doce, Minas Gerais. Revista Ceres v.61 n.4, 2014. Disponível em:< http://dx.doi.org/10.1590/0034737X201461040008 > doi: org/10.1590/0034-737X201461040008

FLECK, N. G. RIZZARDI, M.A.; AGOSTINETTO, D.; VIDAL, R.A. Produção de sementes por picão-preto e guanxuma em função de densidades das plantas daninhas e da época de semeadura da soja. Planta Daninha, v. 21, n. 2, p. 191-202, 2003. Disponível em: <http://dx.doi.org/10.1590/S0100-83582003000200004 > doi: $10.1590 /$ S0100-83582003000200004

FLECK, N. G. Manejo e controle de plantas daninhas em arroz irrigado. In: Vargas, L.; Roman, E. S. (Eds). Manual de manejo e controle de plantas daninhas. Bento Gonçalves: Embrapa Uva e Vinho, p. 251-321. 2004.

GALON, L.; AGAZZI, L. R.; VARGAS, L.; NONEMACHER, F.; BASSO, F. J. M.; PERIN, G. F.; FERNANDES, F. F.; FORTE, C. T.; ROCHA, A. A.; TREVISOL, R.; WINTER, F. L. Competitive ability of canola hybrids with weeds. Planta Daninha, v. 33, n. 3, p. 413-423, 2015. Disponível em: http://dx.doi.org/10.1590/S010083582015000300004 doi: org/10.1590/S0100-83582015000300004

OLIVEIRA, A. R; SIMÕES, W. L. Manejo de Palhada para o Controle de Plantas Daninhas na Cultura da Cana-de-Açúcar Irrigada. Circular Técnica 106, Embrapa, 2014. ISSN 1808-9976

FEY,R.; SCHULZ, D. G.; DRANSKI, J. A. L.; JÚNIOR, J. D.; MALAVASI, M. M.; MALAVASI, U. Identificação e interferência de plantas daninhas em pinhão-manso. Revista Brasileira de Engenharia Agrícola e Ambiental, v.17, n.9, p.955-961, $2013 . \quad$ Disponível em: <http://dx.doi.org/10.1590/S141543662013000900007 >doi:org/10.1590/S1415-43662013000900007.

SEVERINO, L. S.; CARDOSO, G. D.; VALE, L. S. do; SATOS, J. W. dos. Método para determinação da área foliar da mamoneira. Revista Brasileira de Oleaginosas e Fibrosas., v.8, n.1, 2004. Disponível em: http://www.cnpa.embrapa.br/produtos/mamona/publicacoes/2005/BOLETIM55.pdf

SILVA, C.; SILVA, A. F.; VALE, W. G.; GALON, L.; PETTER, F. A.; MAY, A.; KARAN, D. Interferência de plantas daninhas na cultura do sorgo sacarino. Bragantia, v. 73, n. 4, p.438-445, 2014. Disponível em:< http://dx.doi.org/10.1590/1678-4499.0119> doi:org/10.1590/1678-4499.0119.

SIQUEIRA, R. H. S.; FERREIRA, M. M.; ALCÂNTARA, E. N. A.; CARVALHO, R. C. $S$. Agregação de um latossolo vermelho-amarelo submetido a métodos de controle de plantas invasoras na cultura do café. Revista Brasileira Ciência do Solo, 
38:1128-1134, 2014 Disponível em:< http://dx.doi.org/10.1590/S010006832014000400008 > doi:org/10.1590/S0100-06832014000400008.

SOUZA, M. C.; PARREIRA, M. C.; AMARAL, C. L.; ALVES, P. L. C. A. Emergência de guanxuma (Sida rhombifolia) em diferentes épocas e profundidades de semeadura. Biociência. J., v. 28, n. 5, p. 718-724, 2012. Disponível em: <http://dx.doi.org/10.1590/S0034-737X2011000600011> doi:org/10.1590/S0034737X2011000600011.

TAIZ, L.; ZEIGER, E. Fisiologia vegetal. Porto Alegre - RS: Artmed, 2013. 5ed.

VOGT, G. A.; JUNIOR, A. A. B.; TREZZI, M. M.; HEMP, S.; NICKNICH,W. Relação de interferência mútua entre plantas daninhas e sete cultivares de feijão do grupo Carioca. Agropecuária Catarinense, v.27, n.2, p.88-93, 2014. Disponível em: <http://dx.doi.org/10.1590/S0100> doi:org/10.1590/S0100. 